\author{
Jens Schröter
}

\title{
Erasure as planned obsolescence
}

\author{
...she did the honours, \\ Gave me a sidelong look, poured the wine, missing her glass. \\ Over the table it spilled, and with dainty finger she doodled - \\ There, on the wet wooden page, circles of moisture she traced. \\ My name she mingled with hers; I eagerly followed her finger, \\ Watching its every stroke, and she well knew that I did. \\ Quickly at last she inscribed a Roman 'five', with an upright \\ 'One' in front of it - then, when I had seen this, at once \\ With arabesque-like lines she effaced the letters and numbers...
}

Goethe, Roman Elegies [1795]; (Goethe 79)

\section{The Centrality of Erasure}

When the decay and deletion of images are mentioned, we immediately think of badly ventilated archives and iconoclasts. Absent-minded archivists and religious or political fanatics come to mind. However, the present article adresses neither the history of an archival dilettantism deemed worthy of recording nor politically or religiously motivated iconoclasm. In both of these cases, the destruction of images is linked to the destruction of the material that carries them. The information conveyed by the images was meant to endure, but disappeared as its carrier medium was destroyed by negligence or violence.

However, there have long been media primarily intended for recording written information and (simple) images not for a long, but a short period of time - media that served as notes, sketches, memory aids (e.g. sketchbooks or post-its). To be precise: there is a difference between storage and archive.[1] Those records which, unlike the archive, are temporary,[2] either work with an excessive waste of cheap carriers - we need only to think of post-it notes - or they need to erase information in order to create space for new notes. Sometimes information is erased because secret or confidential information has to be made unreadable. But in either case the erasure of information plays a role : the interesting point of 
the nowadays quite popular social media network Snapchat is that sent messages only have a short lifespan and destroy themselves:
"Beginning under the name 'Picaboo', the idea was to create a selfie app which allowed users to share images that were explicitly short-lived and self-deleting. The temporary nature of the pictures would therefore encourage frivolity and emphasize a more natural interaction. [...] [The founders of the company] present Snapchat as the solution to stresses caused by the longevity of personal information on social media."(Wikipedia)

The self destruction of the information is implemented here to avoid that the information gets into the wrong hands, but it is not about confidential and classified information in the institutional sense, but about personal information that might be embarrassing. That the Internet never forgets, as is said, is a big problem for many people and so the idea to develop an app that destroys information after a while is an interesting one. Yet, Snapchat is only the popular tip of the iceberg. There is a huge discussion in computer science on how to develop self-destruction schemes for confidential data. Here is just one example:

"As more and more services and applications are emerging in the Internet, exposing sensitive electronic data in the Internet has become easier. We propose a secure selfdestructing scheme for electronic data (SSDD), which can protect a user's sensitive electronic data by making the sensitive data automatically destructed after a period of time." (Wang et al.)

This self-destruction is a form of erasure. Erasure will form the topic of this article. The media and practices of erasure are obviously a form of planned obsolescence, insofar the information is willfully and intentionally erased.

Erasure has a long history: wax tablets were invented in Greece around the middle of the first millennium. Beeswax darkened with soot was poured onto thin wooden boards shaped like trays, and once hardened could be written upon by scratching the surface with a stylus. The flattened end of the stylus could be used to erase the writing once again.

Blackboards and slate pencils were still used in schools in both German states up until the 1970s; blackboards, chalk and rags for wiping are still used to the present day (Müller). Another widely known but much more recent example is of course the eraser, which was produced on an industrial level from the end of the 19th century onwards and is able to remove traces of graphite (and similar substances) to a large degree without doing too much damage to the carrier medium.[3]

The examples of the comparatively soft graphite, the even softer chalk and the wax tablet show that erasure is only possible with more or less viscous substances - like the wine in Goethe's Elegy - that is, substances that can be returned to their amorphous original 
condition, but these carriers cannot be so fluid that forms dissolve immediately (which is why Goethe's wine only works on a horizontal tabletop). However, they should not fix the forms to such an extent that they cannot be dis-in-formed. A certain similarity to Luhmann's differentiation between medium and form (see below) is obvious.

At any rate, it is obvious that newer substances have appeared since Goethe's wine, whose processes of formation and deletion are not accomplished through physical means (whether through the delicate fingers of a girl, a spatula-shaped stylus, laborious erasing or wiping), but through the effect of electromagnetic fields: a new temporary storage medium another difference between storage and archive.[4]

Modernity not only witnessed the invention of technical storage media that permanently recorded certain aspects of reality in its contingent distribution, such as indelible photographs [5] and films and the equally indelible cylinders, shellac and later vinyl records of phonographs, gramophones and record players (Kittler, Grammophon Film Typewriter 35173).[6] There was also (with a certain time lag, initially often caused by technology[7]) development of (potentially) temporary storage devices on a massive scale. Every indelible technological medium appears to have an erasable counterpart: audiotape, video and so on, and later the erasable digital recording media (such as floppy discs, streamers or USBSticks).[8] There is also a huge difference between the typewriter and any version of Microsoft Word in that with the former, any mistake will have to be laboriously painted over with Tipp-Ex - which is the main reason why a computer using Word (to paraphrase Kittler) is the better typewriter. The distinction between permanent and erasable apparently stands at cross-relations with the difference between analog and digital. Be that as it may, there probably never were as many erasable media, that is, temporary storage materials, as in the 20th century - following Martin Warnke, we might see the oft-cited internet as the apotheosis not of the archive, but of temporary storage (esp. 271-73) - although this description seems nowadays outmoded again, as the internet does not forget. Its design could have included more features for the erasure of information, but this seems not to be the case nowadays.

It is in the twentieth century that the relevance of erasure becomes fully apparent - in psychoanalysis, for example: even before the invention of electromagnetic storage, in his aptly named "Note upon the "Mystic Writing Pad"” (1925) Freud made reference to a recording technique that is no longer widespread today but that used to be popular in my childhood, citing it as the model for the mental apparatus. The mystic writing pad, a wax tablet covered by several layers of cellophane, allows information to be recorded, but can be erased immediately, and - this is the point of Freud's reflections - leaves traces of what has 
been recorded despite the erasure. For Freud, this phenomenon of remanence operated as a metaphor for the unconscious, as Derrida puts it succinctly in his reading of Freud: "The wax slab, in fact, represents the unconscious" (Derrida, 110). While Socrates had already used the wax tablet as a metaphor for memory in Plato's dialogue Theaitetos (Platon 307), the resumption of this metaphor in the 20th century and the shift in emphasis towards the dialectics of erasure (Theaitetos is more concerned with fading traces) and conservation could be seen as symptomatic of the medial operations of modernity.[9] Remanence, which Freud cited as a characteristic of the subconscious, is the key problem of every erasure and in our day, has resulted in completely new data recovery authorities and industries as well as technologies capable of truly complete erasure.[10]

Only a few years after Freuds musings on erasure in a metaphorical machine Turing's 1936/37 thought experiment of a universal computing machine as the logical original pattern of all digital computers also reveals the importance of erasure. The machine's writing and reading head not only records signs: "in other configurations it erases the scanned symbol" (Turing 231)[11] - of course, without destroying the paper tape that forms its basis as a medium. This logical structure also applies to today's computers: their tabs and memory have to be erasable - otherwise algorithmic operations cannot be carried out.

A further well-known discourse to which an implicit connection to erasable storage could be imputed is - as already hinted at above - systems theory, that is itself based on the discursive formation of cybernetics (and therefore indirectly on the Turing machine): Luhmann, who introduced the distinction between medium and form into his model in 1986 (Luhmann, "Das Medium der Kunst"), explicitly describes the medium, which possesses "a certain viscosity" (Luhmann, Die Wissenschaft der Gesellschaft 53) and is thus able to temporarily take on forms, using the metaphor of the "wax mass that suffers the engraving and erasure of inscriptions" (Luhmann, Art as a Social System 103).[12]

So not only are certain aspects of psychoanalysis unable to exist without erasure; so are computers and some facets of the media theory of systems theory. Perhaps erasure as a form of planned obsolescence of information is a key epistemic trope of the 20th century: in Foucault's oft-cited and ominous prediction in the famous conclusion of the Order of Things of 1966, "man" is compared to "a face drawn in sand at the edge of the sea", perhaps soon to be "erased" (422).

Be this as it may, taking these observations as our starting point, a history of erasure would need to address a number of complex questions: what can be temporarily stored at a given point in time and what cannot? What are the rules governing erasure and remanence - 
what is deemed worthy of being stored, who has access to the temporary storage, who is allowed to erase what and at what time, what remains, what is not allowed to endure?[14] What is deliberately made indelible?[15] What is the effect of the historical relationship between storage and archive upon the economies of discourse and memory? And how is this complex linked in turn with dominant socio-economic formations? What happens if the forms of temporary storage multiply and become accessible to more and more people, as happened in the 20th century? Naturally, I do not have answers to all of these challenging questions and even if I had them it would be impossible to deal with them within the scope of the present chapter. Here, we can only clarify some of these questions. We will be concerned with video, a medium that was designed to be erasable from the start. In video the planned obsolescence of information is part of the technical design. Furthermore, we will examine a work of art that has already taken some of these issues as its topic.

\section{The Erasable Image: Video}

The first electromagnetic storage media recorded air vibrations transformed into electric currents, that is, sounds. A technique for doing this based upon a magnetized wire was patented by Valdemar Poulsen in 1898 and even received an award at the 1900 World Exhibition in Paris. However, the sound it produced was only of low quality. Following the development of tape coated with magnetizable emulsion and a new recording head, AEG presented their Magnetophon K-1 in Berlin at the 1935 Radio Exhibition. In 1940, highfrequency premagnetization was invented, which made it possible to record in the sound quality usual in the late $20^{\text {th }}$ century, before digitization began. After 1945 there was an upsurge in the development of recording audiotape technology, which previously had not been paid much attention in the USA. After the end of the War, Major Jack Mullin had four K-4 tape recorders confiscated in the defeated 'Third Reich'. And this way Ampex, which at that point in time was still only a small company, gained the knowledge needed to develop viable tape recorders.

Due to their high frequency range, recording video signals is more difficult than recording sound. However, with the explosion of the television industry (between 1948 and 1955, the percentage of American households in possession of a television rose to fifty percent) the electromagnetic recording of images became an increasingly urgent concern: TV producers needed a medium for recording shows in order to broadcast them at a later point in 
time; for recording daily reports, and so on. Initially film (kinescope recording[16]) was used for this.

However, the time needed to develop the films clashed with television's need for upto-date material. Furthermore, the fact that films used for a current event, for example, could not be reused, meant that the costs were high. Around 1954, television channels used more film as interim storage than all of the Hollywood studios for their movies. Indelibility was expensive. Accordingly, it is hardly a surprise that from around 1948 onwards, Bing Crosby Enterprises, the BBC, RCA and others were all urgently engaged in developing a magnetic technique for recording images. Ampex finally succeeded: on April 14, 1956 they unveiled the Ampex Mark IV, which thanks to two new techniques[17] was the world's first viable video recorder.

Figure 1: Kinescope vs. electromagnetic recording. The upper image shows the film-based process. Without explaining the technical details, it is still obvious that the videographic process represented below is considerably simpler.

Figure 2: The Ampex team of developers with the Mark III, 1957

\section{The Erasure of Work/The Work of Erasure}

Walter Benjamin, in his well known essay The Work of Art in the Age of Mechanical Reproduction famously thought that technical media of reproduction possessed revolutionary and democratizing potential able to eliminate the coercive conditions of bourgeois society. However, in his correspondence with Benjamin, Adorno already argued that the technologies of reproduction had themselves emerged within the capitalist form of society - and the development of video technology, which was more or less forced by the television services for economic reasons, seems to be a telling confirmation of this. The history of technological visual media can also be seen as the gradual industrialization of the visual field, which initially consisted in the emancipation of visual information from its material referent. As early as 1859 , Sir Oliver Wendell Homes wrote of his experiments with the stereoscopic reproduction of photographic images:

"Form is henceforth divorced from matter. [...] Give us a few negatives of a thing worth seeing, taken from different points of view, and that is all we want of it. Pull it down or burn it up, if you please. [...] Matter in large masses must always be fixed and dear; form is cheap and transportable." (747-48). 
This also means that images are now detached from their inert materiality and are able to circulate on the market: "Already a workman has been travelling about the country with stereographic views of furniture, showing his employer's patterns in this way, and taking orders for them" (Holmes 748).[19]

However, photography itself creates material visual objects that travelers have to transport to their destination, as Holmes' reference to the traveling salesman shows. Images transformed into electric signals through scanning are able to avoid this problem: they can be transferred to any location (in principle). Thus, it is hardly a coincidence that the various developments in the fields of telephony, telegraphy and image telegraphy all emerged during the second half of the 19th century in the time of European Imperialism - which on the one hand was made possible by these inventions and on the other hand facilitated their development (Neuburger).

Figure 3: Bakewell's “Copying Telegraph”, 1851. The first viable technique for telegraphically transferring images, that is, transforming them into electric signals.[20]

This means that the industrialization of the visual not only separates visual information from its referent, but also increasingly separates it from its carrier (turning it into transmittable information). It becomes dematerialized, ultimately in the service of total mobilization.

With video, images are created and stored directly in a transferable, electromagnetic form. Ever since then, they have been erasable: image carrier material is saved and it is possible to avoid the accumulation of "useless" archives (although of course everyone is at liberty to amass erasable storage media in gigantic archives - except that video is not really suited to this in the long term, see below). The images are supposed to be suitable for quick exploitation, leaving no waste behind; they no longer seem to possess any value in and of themselves and are as exchangeable as the money to which Holmes already explicitly compared photography (748). One function of the erasure of images is thus the creation of space for the consumption of new images. Contrary to Benjamin's media optimism, there appear to be grounds to suspect that the reproducibility and ephemerality he observed so acutely actually equate to the increasing adaptation of the formerly auratic and materially inert images to the compulsion exerted by capitalism to "melt" all "solid" conditions "into air" (Marx and Engels 38). For this reason alone, video technology's commercial success is hardly surprising.

And this melting into air simultaneously means the erasure of work: in video (as well as in some forms of later digital electromagnetic storage media), the work involved in erasure 
is reduced to a minimum. There is no need for any tortuous rubbing out. With video, in principle only a single erase head is required to return the magnetizable particles in the emulsion to their unordered state, while writing the image needs several heads on the head drum.[21] We could perhaps state that the videographic image is at least conducive to the eradication of work - for however arduous and loving the filming process was, one new recording is enough to erase everything. Seen in this way, the erasure of work (in favor of the reusability of the carrier) is in fact the work of all erasable media.[22] Video seems to be part of the process in which technology eradicates work.

\section{Erasure, Economy and Ecology of the Archive}

Figure 4: William Eggleston, photograph taken from The Louisiana Project (1980).[23]

In his wonderful short story "Last awning flaps on the pier", written in 1965, Williams Burroughs describes a city constructed of old photographs: "On closer inspection the houses are seen to be made from old photos compacted into blocks which give off a sepia haze pervading the room streets and terraces of this dead silent rubbish heap of the past times [...].” (Burroughs 39).

As early as 1927, Kracauer described the amassing of industrially produced images as a threat to collective memory. He wrote of the claim of photographs in illustrated magazines to remind viewers of the objects, people and events represented, that is, their "original images":

"In reality the purpose is not to refer to the original images of the photographic weekly ration.

If it were meant as a prompt and support for memory, then memory would have to make the selection. However, the flood of images sweeps away all of its dams." (Kracauer 34)

It is possible that the analog, electromagnetic, erasable image represents not only a further stage of the industrialization of vision, but also a response to the amassing of images and waste images - the "dead garbage heap of the past" linked with the photographic mass media. We need to be able to get rid of the signs again. Not only can video images be erased, their carrier is also less durable than that of photographic images, which is why videos are not really suitable for the creation of permanent archives.[24] In general, we can observe that the lifespan of the carriers is reduced in many cases, while the data density of the storage media and thus the risk of data loss increases (Zimmer).[25] The fleetingness of recordings and thus also of the images recorded seems to increase in parallel to their sheer quantity, repeatability, 
accessibility and availability - maybe for the simple reason that otherwise we run the risk of a collapsing economy of memory. In 1874, Nietzsche already warned of an antiquarian history threatening to strangle everything (20). In this sense, at least, we might say that "entropy [...] is the other side of the archive" (Ernst 126). The main problem in the age of digital networks is that relevant information is becoming increasingly hard to find in the flood of available data (cf. Schröter). The erasure and/or decay of information (whether intentional or accidental) would thus serve an ecological function within our memory - and Winkler has thus called for an equivalent to forgetting, that is, compressing and relocation, for data networks (172-84). In way this turned out to be a failed utopia, since data networks and the ominous 'cloud' seem now unable to forget.

Given the inflation of hugely diverse images and their increasingly short storage life, the work of historians and archivists is becoming more and more difficult and expensive. What remains, what is erased and what decays? The pictures' fleetingness may lead directly to a kind of market-driven Darwinism of images (Batchen). The question of who has control of the archive, who prevents, permits or even orders erasure (the book burnings of the National Socialists are a barbaric example, albeit an almost atavistic one considering the level that media development had reached at the time) is a pressing one. More precisely: who decides which erasable and/or decaying images are turned into inerasable ones and which are not?

This question requires a detailed analysis of the institutions and their discourses, which lies beyond the scope of the present essay. However, we should by no means settle for silent erasure, a market-driven Darwinism of "weak" images. We might counter this with the (Benjaminian) utopia of a differently organized erasure, conservation and rearrangement of the visual archive that would carry out a different kind of memory work with the images. This alternative might be art.[26] But the topic here is not an archive based on indelible media[27]. Our topic is erasure, which poses the question of what can and should form part of the archive with fresh urgency.

But how is art to deal with erasure? The first problem we are confronted with is that something erased has disappeared and can no longer be thematized as an aisthetic perceivable - phenomenon. Therefore it is a challenge to find an example from video art. For in video, the remanences of electronic erasure are quite simply impossible to detect (except for data retrieval specialists). Perhaps we must firstly seek for a reflection of erasure precisely where the remanences are not yet invisible to people's perception; or where what has been erased is visible ex negativo as a hole. 
But there might be another reason for why no fitting example from video art can be found: the aim of those artists working with the fleeting video image must be to translate their records to the permanence of the museum archive.[28] It is the pressure of the art system that leads to a suppression of the erasability specific to the video medium. Any artistic reflection upon this mode of recording hardly seems possible (even though some early video artists welcomed video as an affront to "auratic" art - however, as soon as they become caught up in the discourse of the museum, it becomes imperative to render the video tapes durable). Perhaps secondly we need to seek for a reflection of erasure where it is not a specific media trait and thus a problem of the museum archive. Rauschenberg's "Erased de Kooning Drawing" meets both of these criteria.

\section{The Art of Erasure}

In 1953, shortly before the emergence of electromagnetic erasable images, in a pioneering act Robert Rauschenberg rubbed out a drawing by Willem de Kooning - thus pre-empting some of the questions that were to arise alongside the erasable images. At first glance this act appears simply to have been an act critical of the archive, given that de Kooning was one of the leading exponents of the so-called "abstract Expressionism" that young artists such as Rauschenberg were respectfully trying to move beyond (or overwrite). However, Rauschenberg stated in a 1976 interview that “[i]t wasn't a gesture, it had nothing to do with destruction", especially since the picture could have been destroyed much more easily through other means (such as burning the paper). Rauschenberg devoted four weeks to erasing all but a few traces of the image information without damaging the carrier (Gamboni 278-79). This distinguishes Rauschenberg's fittingly named work not only from any kind of overpainting (for example in the style of Ad Reinhardt), but also from the negation of work in the video image, even though his emphasis on the difference between image information and carrier in turn appears to point to the erasable images. Thus, Rauschenberg highlights the fact that- material interventions, rather than just a "natural" (read: market-driven) establishment process, determine what is erased and what we will be able to remember in future.

Figure 5: Robert Rauschenberg, Erased de Kooning Drawing (1953)

Through his elaborate work of erasure, Rauschenberg creates value - a work - on the basis of the transformation of work, of $a$ work (the de Kooning drawing). This is emphasized by the 
striking frame, which is decorated with gold leaf and thus conveys a sense of value; according to an inscription on the back of the work, the frame forms part of the work and may not be removed.[29] Thus it is precisely the value of work in the transformation of past work that is thematized - something all too easily forgotten when it comes to throwaway images. However, in order for this hypothesis to be correct, we would need to be sure that Rauschenberg really erased a de Kooning drawing. This is hard to detect from a nearly empty sheet of paper;, despite from what Rauschenberg says, it could have been something else. On the back of the sheet, however, is another drawing by de Kooning, which, according to the MoMA website, is supposed to guarantee its genuine origins. What has not been erased does not belong to the archive, but guarantees that what has been erased and what is missing is part of the archive. Another suspicion arises: might not the erased sheet originally have formed the reverse of the "actual" work, which is now on the other side? Rauschenberg confuses the standard logic of the archive, of which the non-erased and/or front are normally part.

Figure 6: Robert Rauschenberg, Erased de Kooning Drawing (1953), back of the drawing

When looking more closely at the Erased de Kooning Drawing (Figure 5) we can see that the sheet is only nearly empty. Remanent traces remain after Rauschenberg's application of the logic of fleeting drafts or notes to a work[30] that itself was a drawing. Pale grey, shadowy, serpentine lines suggest that they are the remains of the vanished drawing. The viewer is urged to search for traces of de Kooning's drawing, just as data retrieval specialists reconstruct erased data. And this gives rise to a question: what is the smallest amount of traces necessary to call a work a de Kooning? The (artistic) image is taken to the very limits of the conditions of its being.

Moreover, the remanences reveal more than this: the whitish "cloud" on the paper, a trace that is hardly present, refers to the the stresses the carrier material was subjected to: the work of erasure is documented in visual terms. On the other hand, it shows that at least one minimal remanence must exist in order for what has been erased to become noticeable as a hole, so that the act of erasure and thus the erased can actually be perceived as erased. That is - erasure can only become manifest in its failure. This is also demonstrated by the black and brownish spots along the right-hand edge of the picture: it is hard to erase the drawing thoroughly and completely - and thus there are always traces that inadvertently become part of the archive. In this way, Rauschenberg on the one hand takes the economy of memory in miniature as his theme. For on both the individual and the collective level, this economy 
operates through the interconnection of the note/sketch, the temporary, storage and short-term memory, and the work, the permanent, the archive and long-term memory. Rauschenberg evokes both that interlinking of erasure, remanence and the archive and the subsequent torsion of front and back that Freud already emphasized in his discussion of the subconscious and the metaphor of the mystic writing pad (Hombach). Then again, scarcely 20 years after the invention of the audiotape and shortly before the appearance of electromagnetic image storage, Rauschenberg (unintentionally, in this case) predicts those problems of data security that arise as a result of the fact that hardly any erasure really erases everything, and that erasure thus has a denunciatory, subconscious aspect.

\section{The Uncertainty of Erasure}

We are indeed in the grip of uncertainty when erasure is concerned. I have only been able to briefly sketch the key role played by erasure in a range of very different and significant phenomena of the 20th century: in psychoanalysis, in the television industry, computers, video and (with some restrictions) the media theory of systems theory. We are only beginning to imagine how much research would be necessary to investigate more precisely its role - and how it is a central form of planned obsolescence. For example, we would have to archaeologically reconstruct how the epistemic trope of erasure has changed with the development of specific erasable storage media.[31] Thus Freud, given a lack of alternatives, of course referred to the wax tablet and its contemporary, significantly modified version, the mystic writing pad. Turing may have been familiar with the audiotape, but he remains focused upon the eraser - which however makes no difference to its logical design.[32] Then the question arises of why the paradigm of the wax tablet still plays such a central role in theories emerging long after audiotape and video and even digital storage, as Luhmann's example shows. For in the media theory of systems theory (at least after the differentiation between medium and form introduced in 1986), digital media take on a prominent position alongside the wax tablet only very late - and not as the object of investigation, but as a reflexive theoretical metaphor...[33]

This is the complex historical background in front of which the discussion of 'ephemeral communication' takes place. A paper from 2005 on a software solution called the ephemerizer reads: 
"This paper is about how to keep data for a finite time, and then make it unrecoverable after that. It is difficult to ensure that data is completely destroyed. To be available before expiration it is desirable to create backup copies. Then absolute deletion becomes difficult, because even after explicitly deleting it, copies might remain on backup media, or in swap space, or be forensically recoverable. The obvious solution is to store the data encrypted, and then delete the key after expiration. The key is somewhat easier to manage, because it is smaller, but there is still the issue of needing to make the key reliably available for some time, and then reliably destroyed. It is difficult enough for a user to manage one key, much less different keys for different data expiration times. The user could keep each key on a tamperproof smart card with no copies, but then the data will be lost prematurely if the user loses the smart card. And smart cards are expensive. So the idea in this paper is to concentrate all the key management expense and expertise in one place, a server we call an 'ephemerizer'. The ephemerizer creates keys, makes them available for encryption, aids in decryption, and destroys the keys at the appropriate time. The design in this paper ensures that even if a client's machine gets compromised, and everything in stable storage (including long term user keys) is stolen, any data that has expired before the compromise remains unrecoverable." (Perlman)

Here we can see, that the problems of erasing information foster new ideas for solutions e.g. new forms of encryptions and then destroying the key. In a way it's about implementing forgetting into online data. In Snapchat information is erased - but as is argued in the quote, it is difficult to ensure erasure. In Snapchat you can always make a screen shot - although the sender is informed of that; but you can repress this function. There are special apps which simulate a Snapchat account and store the information and finally there is always the 'analog hole', meaning you can always take a photo of the message on your smartphone with another smartphone or camera, there is no way to avoid that. All these questions are part of a new discussion on the economy and ecology of the archive. Now that the possibilities of erasure and destruction of data are not used in a way our desire for privacy would wish, new secondary mechanisms are discussed - to produce a planned obsolescence of information, be it by encryption or deletion.

Be that as it may - it should have become clear that the question of erasure is one that concerns us all in concrete terms: we do not know how long our storage will physically last, or whether someone will delete our storage at some point. Who decides what is allowed to move from temporary storage to the archive? What remains and what decays? Should we have taken greater care to preserve fleeting records such as sounds, writings or pictures? And 
even if we wanted to erase them, we still have the uncertainty of whether the erasure is sufficiently deep. Do remanent traces remain if we delete sensitive data - such as love letters, illegal pornography, trade secrets or other problematic facts? Traces that may betray us, like a face carelessly traced in the sand on the shore.

\section{References}

ACE Data Group. <http://www.datarecovery.net/>. 25 December 2003.

Adorno, Theodor W. "Letter to Walter Benjamin." Gesammelte Schriften I.3. Eds. Rolf Tiedemann and Hermann Schweppenhäuser. Frankfurt am Main: Suhrkamp, 1974. 1000-6. Ahrendt, Jens. "Ausgedreht: Hardwarenahe Datenrettung in Spezialla-bors." c't 5 (1997): 208-17.

Assmann, Aleida. Cultural Memory and Western Civilization. Cambridge: Cambridge University Press, 2012.

Barthes, Roland. Cy Twombly. Berlin: Merve, 1983.

Batchen, Geoffrey. "Photogenics/Fotogenik." Camera Austria 62/63 (1998): 5-16.

Benjamin, Walter. The Work of Art in the Age of Mechaical Reproduction. Trans. J. A. Underwood. London: Penguin, 2008.

Bremer, Lars, and Axel Vahldiek. "Auf Nimmerwiedersehen: Dateien rich-tig löschen." c't 5 (2003): 192-3.

Buchloh, Benjamin H. D. "Gerhard Richters Atlas: Das anomische Archiv." Paradigma Fotografie. Fotokritik am Ende des fotografischen Zeitalters. Volume 1. Ed. Herta Wolf. Frankfurt am Main: Suhrkamp, 2002. 399-427.

Burroughs, William S. "Salt chunk Mary; Last awning flaps on the pier." San Francisco earthquake 1.2 (1967): 35-40.

Derrida, Jacques. "Freud and the Scene of Writing." Yale French Studies 48 (1972): 74-117.

Derrida, Jacques. “Archive Fever: A Freudian Impression.” Diacritics 25.2 (1995): 9-63.

Descartes, Rene. Meditations and Other Metaphysical Writings. Trans. Desmond M. Clarke. London: Penguin, 1998.

Eggleston, William. Ancient and Modern. New York: Random House, 1992.

Ernst, Wolfgang. Das Rumoren der Archive: Ordnung aus Unord-nung. Berlin: Merve, 2002. Foucault, Michel. The Order of Things. London: Routledge, 2005.

Foucault, Michel. "On the Archaeology of the Sciences: Response to the Epistemology Circle." Aesthetics, Method, and Epistemology. Ed. James D. Faubion, trans. Robert Hurley et al. New York: New Press, 1998. 296-333.

Freud, Sigmund. "A Note upon the 'Mystic Writing Pad'." General Psychological Theory. New York: Simon and Schuster, 1997. 207-12.

Gamboni, Dario. Zerstörte Kunst: Bildersturm und Vandalismus im 20. Jahrhundert.

Cologne: DuMont, 1998.

Getty Images International. <www.corbis.com>. 03 December 2017. 
Goethe, Johann Wolfgang von. Selected Poetry. Trans. David Luke. London: Penguin, 1999. Goldstein, Ann, and Anne Rorimer, eds. Reconsidering the Object of Art. Los Angeles: Museum of Contemporary Art, 1995. Exhibition Catalogue.

Guyau, Jean-Marie. "La memoire et le phonographe." Revue philosophique de la France et de l'etranger 5 (1880): 319-22.

Hagen, Wolfgang. "Die Entropie der Fotografie: Skizzen zu einer Ge-nealogie der digitalelektronischen Bildaufzeichnung.” Paradigma Fotografie. Fotokritik am Ende des

fotografischen Zeitalters. Volume 1. Ed. Herta Wolf. Frankfurt am Main: Suhrkamp, 2002. 195-235.

Holbein, Ulrich. Samthase und Odradek. Frankfurt am Main: Suhrkamp, 1990.

Holmes, Oliver Wendell. "The Stereoscope and the Stereograph.” Atlantic Monthly 13 (1859): 738-48.

Hombach, Dieter. "Katastrophentheorie und Psychoanalyse: Zur To-pologie des Entzugs." Zeit-Zeichen: Aufschübe und Interferenzen zwischen Endzeit und Echtzeit. Eds. Georg Christoph Tholen and Michael O. Scholl. Weinheim: VCH, 1990. 137-56.

Kittler, Friedrich. Grammophon Film Typewriter. Berlin: Brinkmann und Böse, 1986.

Kassung, Christian and Albert Kümmel-Schnur, eds. Bildtelegraphie. Eine Mediengeschichte in Patenten (1840-1930). Bielefeld: Transcript, 2012.

Korn, Arthur. Bildtelegraphie. Berlin: de Gruyter, 1923.

Kracauer, Siegfried. "Die Photographie.” Das Ornament der Masse. Frankfurt am Main: Suhrkamp, 1963. 21-39.

Kümmel, Albert, and Petra Löffler, eds. Medientheorie 1888-1933. Frankfurt am Main: Suhrkamp, 2002.

Luhmann, Niklas. "Das Medium der Kunst.” Delfin 4 (1986): 6-16.

Luhmann, Niklas. Art as a Social System. Trans. Eva Knodt. Stanford: Stanford University Press, 2000.

Luhmann, Niklas. Die Wissenschaft der Gesellschaft. Frankfurt am Main: Suhrkamp, 1998.

Luhmann, Niklas. Theory of Society. Volume 1. Trans. Rhodes Barrett. Standford: Standford Univeristy Press, 2012.

Marx, Karl, and Friedrich Engels. The Communist Manifesto. London: Verso, 2012.

Müller, Klaus. Tafel und Griffel: Geschichte und Entwicklung einer fast vergessenen Schreibtechnik. Landau: K. Müller, 1997.

Neuburger, Albert. Von Morse bis Marconi: die Telegraphie und ihre Rolle im Dienste der Weltwirtschaft und Weltpolitik. Berlin: Ullstein, 1920.

Nietzsche, Friedrich. The Use and Abuse of History. New York: Cosimo Classics, 2005.

Perlman, Radia. "The Ephemerizer. Making Data Dissapear"

$<$ https://www.researchgate.net/profile/Radia_Perlman/publication/228360589_The_ephemeri zer_Making_data_disappear/links/55e9ccc408ae3e1218443686/The-ephemerizer-Makingdata-disappear.pdf $>05$ December 2017.

Platon. "Theaitetos.” Sämtliche Werke. Volume VI. Ed. Karlheinz Hülser, Frankfurt am Main: Insel, 1991. 151-367.

Rabanus, Christian. "Die Profis: Datenrettung in Speziallabors." c't 6 (2000): 130-7.

Rauschenberg, Robert. $<$ http://www.art.a.se/artvandals/08.html>. 1976. 25 December 2003. No Longer Available. 
Rauschenberg, Robert. Retrospektive. Cologne: Museum Ludwig, 1998. Exhibition Catalogue.

Schmundt, Hilmar. "Verräterische Magnetspuren: Speicher von Com-putern, Digitalkameras oder Kopierern werden meist unzureichend ge-löscht, vertrauliche Daten lassen sich leicht rekonstruieren." Der Spiegel 52 (2003): 144-5.

Schröter, Jens. "8448 verschiedene Jeans: Zu Wahl und Selektion im Internet." Pa-radoxien der Entscheidung: Wahl/Selektion in Kunst, Literatur und Me-dien, eds. Friedrich Balke, Gregor Schwering, and Urs Stäheli. Bielefeld: Transcript, 2004. 117-38.

SFMOMA. <https://www.sfmoma.org/artwork/98.298>. 05 December 2017.

Skrandies, Timo. Echtzeit - Text - Archiv - Simulation: Die Matrix der Medien und ihre philosophische Herkunft. Bielefeld: Transcript, 2003.

Talbot, William Henry Fox. "Some Account of the Art of Photogenic Drawing, or, The Process by Which Natural Objects May Be Made to Delineate Themselves without the Aid of the Artist's Pencil." Photography: Essays and Images. Illustrated Readings in the History of Photography. Ed. Beaumont Newhall. New York: Museum of Modern Art, 1980. First published 1839. 23-31.

Turing, Alan. "On Compatible Numbers, with an Application to the Entscheidungsproblem." Proceedings of the London Mathematical Society 42 (1937): 230-65.

Wang, Guojun, Yue, Fengshun, and Qin Liu. “A Secure Self-destructing Scheme for Electronic Data.” Journal of Computer and System Sciences 79.2 (2013): 279-290.

Warnke, Martin. "Digitale Archive." Archivprozesse: Die Kommunikation der Aufbewahrung. Eds. Hedwig Pompe and Leander Scholz. Cologne: DuMont, 2002. 269-81.

Webers, Johannes. Handbuch der Film- und Videotechnik. Poing: Franzis, 2000.

Wikipedia. https://en.wikipedia.org/wiki/Snapchat

Winkler, Hartmut. Docuverse: Zur Medientheorie der Computer. Munich: Boer, 1997.

Zielinski, Siegfried. Zur Geschichte des Videorecorders. Berlin: Wissenschaftsverlag Volker Spiess, 1986.

Zimmer, Dieter E. "Das große Datensterben. Von wegen Infozeitalter: Je neuer die Medien, desto kürzer ist ihre Lebenserwartung." Die Zeit 47 (1999): 45-6.

Image Sources

Figure 1: Kinescope vs. electromagnetic recording. Taken from Zielinski, Siegfried. Zur Geschichte des Videorecorders. Berlin: Wissenschaftsverlag Volker Spiess, 1986, 67. Figure 2: The Ampex team of developers with the Mark III, 1957. Taken from Zielinski, Siegfried. Zur Geschichte des Videorecorders. Berlin: Wissenschaftsverlag Volker Spiess, 1986, 265.

Figure 3: Bakewell's “Copying Telegraph”, 1851. Taken from Korn, Arthur.

Bildtelegraphie. Berlin: de Gruyter, 1923, 9.

Figure 4: William Eggleston, photograph taken from The Louisiana Project (1980). Taken from Eggleston, William. Ancient and Modern. New York: Random House, 1992, 69.

Figure 5: Robert Rauschenberg, Erased de Kooning Drawing (1953). Taken from Rauschenberg, Robert. Retrospektive. Cologne: Museum Ludwig, 1998. Exhibition Catalogue, 92 (Plate 63). 
Figure 6: Robert Rauschenberg, Erased de Kooning Drawing (1953), back of the drawing. <https://www.sfmoma.org/artwork/98.298>. 05 December 2017.

[1] This simple distinction is missed by elaborate philosophical reconstructions of the archive concept. An example might be Skrandies (177-206). In fact the problem of storage is by no means always about the "possibility of permanent archiving" (191).

[2] Of course, formerly temporary carriers, such as an artist's sketches or a writer's notes, can become permanent archives themselves over the course of time.

[3] Cf. the apt comments on the eraser in Holbein (54-58). He also refers to the wonderfully named "Tintenkiller" ("ink killer"), which was able to delete ink; I remember it well from my own school days, especially that teachers demonized it.

[4] Ultimately, this difference can be seen to originate with Hans Christian Oersted, who in $1820-25$ years after Goethe's Elegy - discovered the link between electricity and magnetism using a compass. Despite technological change, this discovery ultimately remains the foundation for audiotapes, videotapes and - transcending the break between analog and digital - discs and hard discs. Also cf. Derrida ("Archive Fever" 17): "the technical structure of the archiving archive also determines the structure of the archivable content even in its very coming into existence and in its relationship to the future. The archivization produces as much as it records the event."

[5] Cf. Hagen (233): "Once exposed, it is impossible to return a film to its original condition. It is not the image's 'referent', but the irreversibility of the exposed material that constitutes photography's 'this is the way it was'-ness, a structural loss that is fixated through the 'development' of the picture." On a side note, it is striking that the greatest problem photography faced in its early days actually was that of fixation and thus preventing fading (although this would not have been erasure in the proper sense of the word, as it would not have been possible to reuse the faded photographic material).

[6] Kittler takes up the topic of the audiotape, but does not refer to the property of erasability that sets it apart from the phonograph, gramophone and record player (Grammophon Film Typewriter 162171).

[7] For example, developments as diverse as new carrier materials (cellulose acetate, 1928), ringshaped magnetic heads (1933) and high-frequency premagnetization (1940) first needed to come together before functioning tape recorders could be developed.

[8] This does not work with CD-ROMs, DVDs and other burnt media, which irreversibly change the carriers material physically.

[9] Thus, Assmann notes (146) "the precise correspondence between the history of technology and the theory of memory. As long as photographic and film analogies engraved their images through traces onto material carriers, memory theory as represented from Proust and Warburg to Freud was dominated by the idea that such traces were solid and inextinguishable. In this age of digital media, however, which no longer engrave but coordinate wires and set impulses in motion, we are swiftly moving away from such theories. Memory is no longer viewed as trace and storage, but as a malleable substance that is constantly being reshaped under the changing pressures and perspectives of the present." Four additions should be made to these important and accurate observations: firstly, some digital media continued to "engrave" - CD-ROMs, for example. Secondly, Assmann neglects the storage of audio data - in 1880, the French philosopher Jean-Marie Guyau thought it completely natural to define human memory in terms of the phonograph (Guyau). Thirdly and more importantly, "inextinguishability", as Assman puts it, ends long before computers with audio- and videotapes. And 
fourthly, we can add on a theoretical note that there can be no question of "inextinguishability" in Freud, even though he certainly regarded memory as a "malleable substance" to some extent - the metaphor of the mystic writing pad helps us to think of conservation and erasure simultaneously.

[10] Schmundt (145): “'In order to properly erase a data carrier [...], the hard disk would have to be completely erased.' Complete erasure means that hard disks are overwritten with specially computed random numbers - 'over 30 times,' according to Pfitzner. Other experts are of the opinion that ten rounds of erasure are enough. However, it is undisputed that this kind of procedure can take several days for large hard disks. Where truly important and sensitive data are concerned, the experts thus recommend anachronistic and violent means: physically destroying the disk by cutting, burning or shredding it." Thanks to Nicola Glaubitz for this source. However, there are also authors who emphasize that overwriting the hard disk completely once, with zeroes for example, is completely sufficient (Bremer and Vahldiek). In the meantime, have emerged entire industries that are specialized in the - sometimes extremely expensive - reconstruction of data that have been apparently irretrievably lost or deleted purposely in order to hide their content; cf. e.g. ACE Data Group and also cf. Ahrendt and cf. Rabanus.

[11] Also cf. Turing (244) where he states explicitly: "The machine [...] erases all letters $x$ and $y . "$

[12] In Descartes' Meditationes de prima philosophia of 1641, the wax mass still had a completely different meaning - there, the focus lay not on the fact that it made erasable notes possible, but rather on the substantial identity of wax throughout all the changes made to it (29-31).

[14] "I shall call an archive, not the totality of texts that have been preserved by a civilization or the set of traces that could be salvaged from its downfall, but the series of rules which determine in a culture the appearance and disappearance of statements, their retention and their destruction" (Foucault, "On the Archaeology of the Sciences" 309; emphasis J.S.).

[15] Here, we would need to untangle the web of technologies and discourses: we might refer to the protection tags familiar from audio cassettes, video cassettes and diskettes on the one hand, and on the other hand to all the rules and regulations - up to prohibitions enforced by the police - that simply forbid any possible erasure.

[16] There was a strange technology, the 1933 so-called "Zwischenfilmsender" ("interlude broadcaster") of the Fernseh AG, which tried to save on film material through deletion. The film formed a continuous loop in the apparatus. After it had served its purpose as interim storage for images, the emulsion was automatically washed off the celluloid, the carrier was recoated and the film could then be reused. However, this technique still wasted emulsion and the quality of its images was too poor to be viable for the American television industry (Zielinski 62-3).

[17] These techniques were firstly transverse recording, where signals are written vertically across the tape using a rotating "quad" head with four head pieces, instead of being written horizontally, which (given the frequency range of video signals) would require the tape to move impossibly fast. This means a sufficiently high write speed can be achieved between head and tape without using extreme amounts of tape (later, vertical writing was replaced by diagonal writing, which made it possible to record one frame per track, for example in order to guarantee clean stills). Secondly, the Ampex engineers used a new kind of frequency modulation. For technical details of video recording, cf. Webers (424-531); on erasure in particular, cf. 440-42.

[19] Between 1850 and 1880, stereoscopy was one of the main ways of viewing photographic images. It is not possible to go into any detail on the particular implications of the stereoscope in the present article.

[20] Later techniques for transforming image information or light (which is by no means the same thing, as Bakewell's dispositif shows clearly) into electricity (video tubes, CCDs) work very differently, of course. Bakewell's image telegraph is simply the first viable device that carried out this transformation (Bain had already presented a prototype in 1843). On image telegraphy in general, cf. 
Korn; Kassung and Kümmel. On other transformations of visual information, cf. Webers (143-50). On the genealogy of CCDs, cf. Hagen.

[21] More elaborate video recorders have several erase heads on the head drum, which makes clean inserts possible.

[22] Incidentally, it is quite striking that the change in the value of work also plays a role in early texts on photography (which then naturally was indelible): "[F]or the object which would take the most skilful [sic] artist days or weeks of labour to trace or to copy, is effected by the boundless powers of natural chemistry in the space of a few seconds" (Talbot 24).

[23] Overall, Eggleston's work does not really fit into a genealogy of erasure - the picture is only being used here as it takes up the issue of photographic waste discussed below in a beautiful manner.

[24] As can be seen in the debate on the museification of video art.

[25] Another problem with digital data is that the data formats and devices for reading them become obsolete over time. After all, who is able to read a floppy disk in this day and age?

[26] Thus, Gerhard Richter, for example, dealt with the problems of photography, archive and memory in his work Atlas (Buchloh). We must leave the question open of whether resistant forms of archiving or erasure could have become established in other (e.g. popular) practices.

[27] The archive can also be based upon erasable media, the erasure of which is however prohibited.

[28] Claire Zimmer drew my attention to an example that works with an erasable audio tape, although not with video. In her work Information: No Theory (1970), Christine Kozlov used a tape recorder in which the tape ran in an infinite loop to record all the sounds in the room the recorder was exhibited in. The recorded sounds were erased and overwritten by the new recordings ("The nature of the tape loop necessitates that new Information erases old Information”, Goldstein and Rorimer 154-55). The same goes for some of Dan Graham's video installations, in which a kind of closed circuit with minimal delay is created. This process only works on the basis of erasable video.

[29] Information taken from SFMOMA.

[30] The same procedure could perhaps be read into Cy Twombly's palimpsestic overwritings and rubbing (Barthes 19).

[31] A fine collection of early proto-media theory texts reveals that erasure played no role in media discourse prior to the development of the magnetophone in 1935 (Kümmel and Löffler).

[32] Turing's thought experiment followed very shortly after the presentation of the magnetophone in 1935. Turing compares his paper machine to a man in the process of computing; the deletion of symbols on the roll of paper (Turing 231) thus is modeled on the eraser. Every human being (including you, dear readers) can become a Turing machine if equipped with a pencil, an eraser, a long paper tape and a status table. As a logical concept, Turing machines can - in principle - be realized in any kind of material. Later on, Kittler notes that, in the context of his military work, Turing considered "building a captured Wehrmacht magnetophone into his projected mainframe computer as data storage" (Kittler, Grammophon Film Typewriter 164-65).

[33] In his magnum opus and last work, Theory of Society, Luhmann thus writes about the coupling between medium and form that forms the foundation of his social theory: "The temporal process of repeated coupling and uncoupling serves both to continue autopoiesis and to form and modify the structures it requires - as with a von Neumann machine" (119). Indeed, nothing (except perhaps the wax tablet) seems to correspond as accurately to Luhmann's concept of the medium, which is nothing without form, as the universal (within the context of what can be formalized and the limits of computer resources) and thus freely programmable, that is, "form-able" machine of Turing and von Neumann. 